\title{
Erratum to: Cosmological framework for renormalization group extended gravity at the action level
}

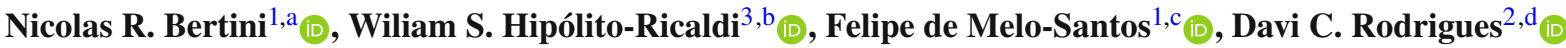 \\ ${ }^{1}$ Núcleo de Astrofísica e Cosmologia, PPGFis, Universidade Federal do Espírito Santo, Vitória, ES, Brazil \\ ${ }^{2}$ Núcleo de Astrofísica e Cosmologia, PPGCosmo, Departamento de Física, Universidade Federal do Espírito Santo, Vitória, ES, Brazil \\ ${ }^{3}$ Departamento de Ciências Naturais, PPGCosmo, Universidade Federal do Espírito Santo, São Mateus, ES, Brazil
}

Published online: 20 July 2020

(C) The Author(s) 2020

\section{Erratum to: Eur. Phys. J. C (2020) 80:479 \\ https://doi.org/10.1140/epjc/s10052-020-8041-4}

The original published version of the article used the symbols $\varepsilon$ and $\epsilon$, but only one of them was defined and should have been used. This typographical error was introduced in the proofs. The new online version corrects this issue by using $\varepsilon$ only.

The original article has been corrected.

Acknowledgements Funded by SCOAP3.

Open Access This article is licensed under a Creative Commons Attribution 4.0 International License, which permits use, sharing, adaptation, distribution and reproduction in any medium or format, as long as you give appropriate credit to the original author(s) and the source, provide a link to the Creative Commons licence, and indicate if changes were made. The images or other third party material in this article are included in the article's Creative Commons licence, unless indicated otherwise in a credit line to the material. If material is not included in the article's Creative Commons licence and your intended use is not permitted by statutory regulation or exceeds the permitted use, you will need to obtain permission directly from the copyright holder. To view a copy of this licence, visit http://creativecomm ons.org/licenses/by/4.0/.

Funded by $\mathrm{SCOAP}^{3}$.

The original article can be found online at https://doi.org/10.1140/ epjc/s10052-020-8041-4.

a e-mail: nicolas.bertini@ cosmo-ufes.org

be-mail: wiliam.ricaldi@ufes.br

c e-mail: felipe.santos@cosmo-ufes.org

d e-mail: davi.rodrigues@cosmo-ufes.org (corresponding author) 